\title{
Patients with neuromyelitis optica have a more severe disease than patients with relapsing- remitting multiple sclerosis, including higher risk of dying of a demyelinating disease
}

Pacientes com neuromielite óptica apresentam doença mais incapacitante que pacientes com esclerose múltipla, incluindo maior chance de falecerem de uma doença desmielinizante Denis Bernardi Bichuetti', Enedina Maria Lobato de Oliveira', Nilton Amorin de Souza', Mar Tintorée, Alberto Alain Gabbai

\begin{abstract}
Although neuromyelitis optica (NMO) is known to be a more severe disease than relapsing-remitting multiple sclerosis (RRMS), few studies comparing both conditions in a single center have been done. Methods: Comparison of our previously published cohort of $41 \mathrm{NMO}$ patients with 177 RRMS patients followed in the same center, from 1994 to 2007. Results: Mean age of onset was 32.6 for NMO and 30.2 for RRMS $(p=0.2062)$ with mean disease duration of 7.4 years for NMO and 10.3 years for RRMS. Patients with NMO had a higher annualized relapse rate $(1.0$ versus $0.8, p=0.0013$ ) and progression index (0.9 versus $0.6, p<0.0001)$, with more patients reaching expanded disability status scale (EDSS) 6.0 (39 versus 17\%, p=0.0036). The odds ratio for reaching EDSS 6.0 and being deceased due to NMO in comparison to RRMS were, respectively, 3.14 and 12.15. Conclusion: Patients with NMO have a more severe disease than patients with RRMS, including higher risk of dying of a demyelinating disease.
\end{abstract}

Key words: neuromyelitis optica, multiple sclerosis, demyelinating diseases, risk factors.

RESUMO

Embora a neuromielite óptica (NMO) seja reconhecida como mais grave que a esclerose múltipla remitente recorrente (EMRR), existem poucos estudos comparando as duas doenças em um único centro. Métodos: Comparação de nossa coorte publicada de 41 pacientes com NMO com 177 pacientes com EMRR seguidos no mesmo centro, de 1994 a 2007. Resultados: A média de idade inicial foi de 32,6 anos em NMO e 30,2 anos em EMRR ( $p=0,2062)$, com tempo médio de doença de 7,4 anos para NMO e 10,3 anos EMRR. Pacientes com NMO apresentaram maior taxa anualizada de surtos ( 1,0 versus $0,8, p=0,0013)$ e índice de progressão $(0,9$ versus $0,6, p<0,0001)$, com mais pacientes atingindo EDSS 6,0 (39 versus 17\%, $p=0,0036$ ). Os riscos relativos de se alcançar 6,0 EDSS e falecer em decorrência de NMO em comparação com EMRR, foram, respectivamente, 3,14 e 12,15. Conclusão: Pacientes com NMO têm uma doença mais grave do que os pacientes com EMRR, incluindo maior risco de morrer de uma doença desmielinizante.

Palavras-Chave: neuromielite óptica, esclerose múltipla, doenças desmielinizantes, fatores de risco.

Neuromyelitis optica (NMO) is an inflammatory autoimmune disease that affects the central nervous system (CNS) associated to significant neurologic disability ${ }^{1,2}$. For many decades, NMO was considered a variant of multiple sclerosis (MS), characterized by recurrent bilateral optic neuritis and transverse myelitis occurring concomitantly or apart in time, and without evidence of disease outside the optic nerves and the spinal cord ${ }^{3}$. Nowadays, studies indicate that NMO is a distinct disease from $\mathrm{MS}^{4}$, with nearly $90 \%$ of patients presenting a relapsing remitting course and half of them exhibiting brain lesions on magnetic resonance imaging ${ }^{2,5}$.

Although NMO is frequently cited to have a more severe clinical course than relapsing-remitting MS (RRMS), few direct head-to-head studies involving both diseases in a single center scenario have been done $e^{6,7}$. We recently published

'Setor de Neuroimunologia, Universidade Federal de São Paulo (UNIFESP), São Paulo SP, Brazil;

${ }^{2}$ Center d'Esclerosi Múltiple de Catalunya-CEMcat, Hospital Universitari Vall d'Hebron, Barcelona, Spain.

Correspondence: Denis Bernardi Bichuetti; Departamento de Neurologia e Neurocirurgia, Universidade Federal de São Paulo; Rua Botucatu 740; $4023-900$ São Paulo SP - Brasil; E-mail: bichuetti@unifesp.br

Conflict of interest: There is no conflict of interest to declare.

Received 23 August 2012; Received in final form 30 November 2012; Accepted 07 December 2012. 
a series of 41 patients with recurrent NMO followed at the Neuroimmunology Clinic of the Universidade Federal de São Paulo (UNIFESP), which showed that incomplete recovery from relapses was the main clinical predictor of future neurologic disability and azathioprine solely or in association with prednisone was able to halt relapses and disability progression in $76 \%$ of the patients ${ }^{2,8}$. In order to better understand the clinical differences between NMO and MS, we compared this cohort of 41 patients with recurrent $\mathrm{NMO}^{2}$ with patients followed for RRMS in the same center.

\section{METHODS}

The Neuroimmunology Clinic of the UNIFESP is a tertiary care center focused on caring for patients with multiple sclerosis and other demyelinating diseases, established in 1994. Since then, the center keeps a database containing all clinical, laboratory, radiological and therapeutic information of the patients.

\section{Cohort}

We retrospectively compared our previously published cohort of 41 patients with recurrent NMO with 177 patients with RRMS followed in the same center, from February 1994 to December 2005 for RRMS ${ }^{9}$ and July 2007 for $\mathrm{NMO}^{2}$. Regular appointments were scheduled every three months in the first year of follow-up and every six months afterwards, unless a relapse or drug adverse event incited an urgent evaluation. All patients were seen and examined by the same physicians along follow-up (DBB, NAS, EMLO and AAG), and clinical and radiological information were retrieved from each patient's file and imputed to a computer database in Microsoft's Excel files in 2005 and 2007 for RRMS and NMO, respectively. These databases were selected for this specific analysis as they were already completed and represent patients from the same time period in a single center setting.

Inclusion criteria for this analysis were: fulfillment of Wingerchuk NMO criteria as per $2006^{7}$ for patients with recurrent NMO, and fulfillment of McDonald 2001 criteria for RRMS ${ }^{10}$. All patients included had at least two appointments and follow-up longer than six months. Patients with relapsing remitting MS seen before the publication of the McDonald criteria, i.e., seen before 2001 and thus classified by the Poser criteria ${ }^{11}$, had their files and magnetic resonance images (MRI) reports reviewed for diagnosis reassurance. Given that it is presumed there is no degenerative process in $\mathrm{NMO}^{12-14}$ and thus patients with NMO do not present with a progressive clinical course ${ }^{12}$, patients with primary progressive forms of MS (primary progressive or relapsing progressive) were excluded in order to perform a more appropriate comparison between MS and NMO.
We collected demographic and clinical data of all patients that met the inclusion criteria. To avoid bias due to disease duration, we divided the expanded disability status scale (EDSS) on last follow-up visit and total number of relapses by the total time of disease (in years), thus using the progression index (PI) and annualized relapse rate (ARR) to evaluate disease progression and severity when comparing the groups of patients. Reaching an EDSS score of 6.0 was considered a hard clinical endpoint of disease severity, as this confers severe disability and impacts on social life. Patients in this study received regular preventive therapies recommended and available for their diagnosis (RRMS or NMO) at the time they were seen, which included, but were not restricted to, interferon beta, glatiramer acetate, corticosteroids, cyclophosphamide, methotrexate, azathioprine and intravenous immunoglobulin, with the exception of five patients with NMO and two with RRMS that received no treatment apart of pulse intravenous steroids for the treatment of relapses.

The statistical analysis was performed using GraphPad Prism version 5.0 (GraphPad Software Incorporated ${ }^{\circledR}$ ). Unpaired $t$ test or Mann-Whitney tests were used when comparing two groups, according to results on KolmogorovSmirnov normality test; $\chi^{2}$ or Fisher's exact test when appropriate. Reaching an EDSS score of 6 was considered a clinical endpoint of disease severity, as this confers moderate to severe disability and impacts on social life. Building a precise Kaplan-Meier curve for estimating the time to assignment of EDSS 6.0, we considered a period of 100 months (8.3 years), which corresponds to the $95 \%$ confidence interval of total disease duration time for the patients with NMO. Data are presented as mean \pm standard deviation (SD), and significance was set at $\mathrm{p}<0.05$. Approval by the Internal Review Board of the UNIFESP was obtained prior to study onset.

\section{RESULTS}

One hundred and seventy seven patients that debuted with RRMS fulfilled the inclusion criteria and were selected to be compared to the 41 patients with NMO previously reported ${ }^{2}$. At the moment of data collection, 129 patients were still categorized as RRMS and 48 (27\%) had evolved to the secondary progressive clinical phase of MS. No differences in age at onset and female to male ratios were found between MS and NMO patients. When comparing time elapsed from first relapse to evaluation at our center, patients with NMO were referred nearly within half the time than patients with MS, respectively, 37.2 ( \pm 47.4$)$ versus 69.0 ( \pm 86.6$)$ months. Patients with MS had a clear predominant Caucasian ethnic background, and patients with NMO had more African (including Brazilian Mulatto) and Asian ancestry background (Table).

Patients with NMO had higher EDSS on first and last appointment, higher PI and ARR, and a greater 
proportion of patients with NMO reached EDSS 6.0 during follow-up than patients with RRMS (Table and Figure). Furthermore, even with shorter disease duration, the odds ratio for reaching EDSS 6.0 and dying due to NMO in comparison to MS were, respectively, 3.14 (95\%CI 1.496-6.576, $\mathrm{p}=0.0036)$ and 12.15 (95\%CI 2.267-65.140), $\mathrm{p}=0.0017$. There were no differences in age of onset and female to male ratio between patients with MS and NMO (Table).

Thirty-six patients with NMO received immunomodulatory or immunosuppressive treatments as previously described $^{8}$. All but two patients with RRMS described here used at least one approved immunomodulatory drug (betainterferon 1a, betainterferon $1 \mathrm{~b}$ or glatiramer acetate), 44 patients changed treatment drug once, and 53 patients switched therapies 3 or more times. Reasons from switching drug in RRMS could be either adverse effects or failure to respond to a specific regimen, and patients were switched either from one betainterferon formulation to another, from betainterferon to glatiramer acetate or vice-versa, or were offered monthly IV cyclophosphamide in severe cases.

\section{DISCUSSION}

Patients with NMO presented in this study had clearly a more severe disease than patients with MS that debuted as RRMS, disclosed not only by PI and ARR comparison, but also by EDSS on first and last evaluations. The Kaplan-Meier estimates expose that more patients with NMO have a higher risk and a shorter time to reach EDSS 6.0, which, associated to a higher odds ratio of being deceased, reinforces the more severe prognosis of patients with NMO than patients with an initial presentation of RRMS. Although patients with NMO had shorter disease duration, this does not affect the analysis through PI an ARR, as data have been divided for the total years of disease to allow proper comparisons. Considering that relapse rate and incomplete recovery from relapses are the key factors correlated with future disability in $\mathrm{NMO}^{2,15}$, the association of higher ARR and PI in NMO than in RRMS strengthens the need to early control of relapse recurrence in patients with NMO.

Past series encompassing patients with NMO have shown a mean age of first symptom of 36 years old $( \pm 4.8)$ and female to male ratio ranging from 2.4:1 to $36: 1^{1,12,16-25}$, which is distinct from the present results. Interestingly, when these series are arranged by date, the most recent works presented results similar to ours ${ }^{16-19}$, while studies published before 2007-2008 presented patients with an older age of onset and more marked female predominance $e^{1,12,20-25}$. It is not clear why these differences exist, and we hypothesize that the increase in knowledge on the disease's pathophysiology ${ }^{4}$, brain and spinal cord imaging $^{2,5,26}$, treatment possibilities ${ }^{8,27-29}$ and broad propagation of the disease's previous ${ }^{1}$ and current diagnostic criteria $^{7,29}$ might have contributed for a wider selection of patients in the later studies. Therefore, the present study suggests that, concerning age of onset and female:male ratio, NMO patients might not differ much from RRMS, and this demographic information should not influence the weighting of one diagnosis over another.

Our study reinforces previous knowledge that the prevalence of NMO is higher in non-Caucasians, as opposed to MS. These differences might be explained by different genetic background between these two patient's population, as the DRB1*1501 HLA haplotype is not associated to $\mathrm{NMO}$ as it is in $\mathrm{MS}^{18,30,31}$. Furthermore, Brazilian collaboration

Table. Demographics and disease evolution of patients with NMO and MS.

\begin{tabular}{lccc} 
& NMO & MS & p-value \\
\cline { 2 - 3 } & $(n=41)$ & $(n=177)$ & 0.2062 \\
Age of onset (years) & $32.6( \pm 11.5)$ & $30.2( \pm 10.5)$ & 0.3429 \\
Sex (F:M) & $2.4: 1$ & $3.8: 1$ & $<0.0001$ \\
Ethnicity & $18(44 \%)$ & $127(72 \%)$ & $5(3 \%)$ \\
$\quad$ Caucasian & $11(24 \%)$ & $0(0 \%)$ & $45(25 \%)$ \\
$\quad$ African & $2(5 \%)$ & $10.3( \pm 7.6)$ & 0.0239 \\
$\quad$ Asian & $10(24 \%)$ & $69.0( \pm 86.6)$ & 0.0368 \\
$\quad$ Mulatto & $7.4( \pm 4.9)$ & $2.4( \pm 2.0)$ & $<0.0001$ \\
Disease duration (years) & $37.2( \pm 47.4)$ & $3.6( \pm 2.7)$ & 0.0013 \\
Time to first evaluation (months) & $3.9( \pm 1.7)$ & $0.8( \pm 0.9)$ & 0.0079 \\
EDSS first evaluation & $5.2( \pm 2.7)$ & $0.6( \pm 1.0)$ & $<0.0001$ \\
EDSS last evaluation & $1.0( \pm 0.8)$ & $30(17 \%)$ & 0.0036 \\
Annualized relapse rate & $0.9( \pm 0.7)$ & $2(1 \%)$ & 0.0017 \\
Progression index & $16(39 \%)$ & \\
Patients reaching EDSS 6, $n$ (\%) & $5(12 \%)$ & & \\
Patients deceased & &
\end{tabular}

NMO: neuromyelitis optica; MS: multiple sclerosis (patients that debuted as relapsing remitting MS), 48 had evolved to a secondary progressive MS along follow-up; EDSS: expanded disability status scale; annualized relapse rate: total number of relapses/disease duration; progression index: EDSS on last appointment/disease duration; time to first evaluation indicates the time elapsed between first symptom and first appointment at our center; F: female; M: male. 


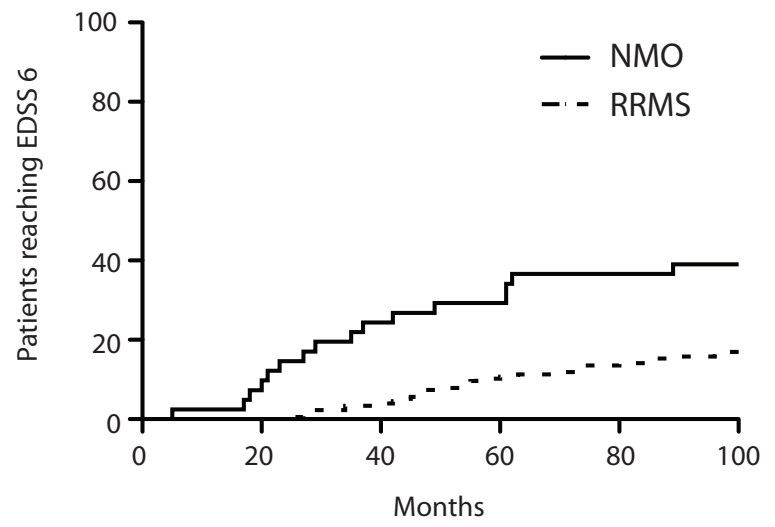

Log-rank (Mantel-Cox) Test $=-0,0003$

Zero denotes time of first symptom, i.e., first clinical relapse. NMO: neuromyelitis optica; RRMS: relapsing remitting multiple sclerosis; EDSS: expanded disability status scale.

Figure. Kaplan-Meier curves for the probability to reach an EDSS score $\geq 6.0$ for patients with relapsing remitting multiple sclerosis (dashed lines) and neuromyelitis optica (black lines).

studies have identified the HLA-DRB1*3 to be overrepresented in $\mathrm{NMO}^{18}$. In this same study, the low frequency of HLADRB1*15 alleles was associated with the presence of long and central cord lesions at magnetic resonance ${ }^{18}$. Although these genetic differences might be associated with the non-Caucasian predominance among patients with NMO, it is not yet clear whether they are related to the disease's susceptibility or pathophysiology mechanisms.
An interesting data observed in this study is the shorter time from symptom onset to first evaluation in our clinic, for patients with NMO in comparison to MS. The Neuroimmunology Clinic of the Universidade Federal de São Paulo is a referral center for demyelinating disease, and patients can schedule an appointment by free will or be sent by their primary care physician or neurologist. We presume that this shorter interval might be due to relapse severity, which impel the need for a specific diagnosis and prompt evaluation at a specialized center.

In addition to being a retrospective study, most patients evaluated in this analysis received immunomodulatory or immunosuppressive treatment, thus we cannot state that our results qualify as a natural history cohort comparison study between diseases. Nevertheless, as 29 patients with NMO received long term preventive treatment with azathioprine, an effective drug for halting relapses in $76 \%$, 27 , the differences in severity between both diseases might have even been greater if both groups of patients did not have received any type of treatment along follow-up.

Our data objectively expose that patients with NMO have a more severe disease than patients with RRMS, including higher risk of dying of a demyelinating disease. We therefore advocate that patients with relapsing NMO should be candidates for early and appropriate immunosuppressive treatment in order to avoid relapses and the accumulation of neurological disability. Nonetheless, clinical trials addressing the real safety and efficacy of immunosuppressive drugs in NMO are mandatory.

\section{References}

1. Wingerchuk DM, Hogancamp WF, O'Brien PC, Weinshenker BG. The clinical course of neuromyelitis optica (Devic's syndrome). Neurology 1999;53:1107-1114.

2. Bichuetti D, Oliveira E, Souza N, Rivero R, Gabbai A. Neuromyelitis optica in Brazil: a study on clinical and prognostic factors. Mult Scler 2009;15:613-619.

3. Lana-Peixoto MA. Devic's neuromyelitis optica: a critical review. Arq Neuropsiquiatr 2008;66:120-138.

4. Jacob A, Matiello M, Wingerchuk DM, Lucchinetti CF, Pittock SJ, Weinshenker BG. Neuromyelitis optica: changing concepts. J Neuroimmunol 2007;187:126-138.

5. Pittock SJ, Lennon VA, Krecke K, Wingerchuk DM, Lucchinetti CF, Weinshenker BG. Brain abnormalities in neuromyelitis optica. Arch Neurol 2006;63:390-396.

6. Lim BC, Hwang $\mathrm{H}$, Kim KJ, et al. Relapsing demyelinating CNS disease in a Korean pediatric population: multiple sclerosis versus neuromyelitis optica. Mult Scler 2011;17:67-73.

7. Wingerchuk DM, Lennon VA, Pittock SJ, Lucchinetti CF, Weinshenker BG. Revised diagnostic criteria for neuromyelitis optica. Neurology 2006;66:1485-1489.

8. Bichuetti DB, Lobato de Oliveira EM, Oliveira DM, Amorin de Souza N, Gabbai AA. Neuromyelitis optica treatment: analysis of 36 patients. Arch Neurol 2010;67:1131-1136.

9. Oliveira EML, Souza NA, Bichuetti DB, Oliveira DM, Annes M, Gabbai AA. Multiple sclerosis in Brazil: 1994-2005, a Brazilian experience.
In: 22nd Congress of the European Committee for Treatment and Research in Multiple Sclerosis (ECTRIMS); 2006. Madrid: SAGE Publications, 2006: S124.

10. McDonald WI, Compston A, Edan G, et al. Recommended diagnostic criteria for multiple sclerosis: guidelines from the International Panel on the diagnosis of multiple sclerosis. Ann Neurol 2001;50:121-127.

11. Poser CM, Paty DW, Scheinberg L, et al. New diagnostic criteria for multiple sclerosis: guidelines for research protocols. Ann Neurol 1983;13:227-231.

12. Wingerchuk DM, Pittock SJ, Lucchinetti CF, Lennon VA, Weinshenker BG. A secondary progressive clinical course is uncommon in neuromyelitis optica. Neurology 2007;68:603-605.

13. Bichuetti DB, Rivero RL, de Oliveira EM, et al. White matter spectroscopy in neuromyelitis optica: a case control study. J Neurol 2008;255:1895-1899.

14. Aboul-Enein F, Krssak M, Hoftberger R, Prayer D, Kristoferitsch W. Diffuse white matter damage is absent in neuromyelitis optica. AJNR Am J Neuroradiol 2010;31:76-79.

15. Bergamaschi R, Ghezzi A. Devic's neuromyelitis optica: clinical features and prognostic factors. Neurol Sci 2004;25:S364-S367.

16. Rivera JF, Kurtzke JF, Booth VJ, Corona Tt. Characteristics of Devic's disease (neuromyelitis optica) in Mexico. J Neurol 2008;255:710-715.

17. Collongues N, Marignier R, Zephir H, et al. Neuromyelitis optica in France: a multicenter study of 125 patients. Neurology 2010;74:736-742. 
18. Brum DG, Barreira AA, dos Santos AC, et al. HLA-DRB association in neuromyelitis optica is different from that observed in multiple sclerosis. Mult Scler 2010;16:21-29.

19. Blanco Y, Hankiewicz K, Llufriu S, Sabater L, Graus F, Saiz A. [Clinical spectrum associated with aquaporin-4 antibodies (NMO-IgG)]. Neurologia 2010;25:5-12.

20. Ghezzi A, Bergamaschi R, Martinelli V, et al. Clinical characteristics, course and prognosis of relapsing Devic's neuromyelitis optica. J Neurol 2004;251:47-52.

21. Wingerchuk DM, Weinshenker BG. Neuromyelitis optica: clinical predictors of a relapsing course and survival. Neurology 2003;60:848-853.

22. Papais-Alvarenga RM, Carellos SC, Alvarenga MP, Holander C, Bichara RP, Thuler LC. Clinical course of optic neuritis in patients with relapsing neuromyelitis optica. Arch Ophthalmol 2008;126:12-16.

23. Papais-Alvarenga RM, Miranda-Santos CM, Puccioni-Sohler M, et al. Optic neuromyelitis syndrome in Brazilian patients. J Neurol Neurosurg Psychiatry 2002;73:429-435.

24. Adoni T, Lino AM, da Gama PD, et al. Recurrent neuromyelitis optica in Brazilian patients: clinical, immunological, and neuroimaging characteristics. Mult Scler 2010;16:81-86.
25. Nakashima I, Fujihara K, Miyazawa I, et al. Clinical and MRI features of Japanese patients with multiple sclerosis positive for NMO-IgG. J Neurol Neurosurg Psychiatry 2006;77:1073-1075

26. Bichuetti DB, Rivero RL, Oliveira DM, et al. Neuromyelitis optica: brain abnormalities in a Brazilian cohort. Arq Neuropsiquiatr 2008;66:1-4.

27. Costanzi C, Matiello M, Lucchinetti CF, et al. Azathioprine: Tolerability efficacy, and predictors of benefit in neuromyelitis optica. Neurology 2011;77:659-666.

28. Jacob A, Weinshenker BG, Violich I, et al. Treatment of neuromyelitis optica with rituximab: retrospective analysis of 25 patients. Arch Neurol 2008;65:1443-1448.

29. Sellner J, Boggild M, Clanet $M$, et al. EFNS guidelines on diagnosis and management of neuromyelitis optica. Eur $\mathrm{J}$ Neurol 2010;17:1019-1032.

30. Matiello M, Schaefer-Klein J, Brum DG, Atkinson EJ, Kantarci OH, Weinshenker BG. HLA-DRB1*1501 tagging rs3135388 polymorphism is not associated with neuromyelitis optica. Mult Scler 2010;16:981-984.

31. Matsushita T, Matsuoka T, Isobe N, et al. Association of the HLADPB1*0501 allele with anti-aquaporin-4 antibody positivity in Japanese patients with idiopathic central nervous system demyelinating disorders. Tissue Antigens 2009;73:171-176. 